\title{
Verwendung des „Doppelkondoms“ bei der TRUS-Biopsie
}

\author{
Wie Sie Verschmutzungen des Ultraschallkopfes und der Punktionshilfe bei der ultraschall- \\ geführten transrektalen Prostatabiopsie vermeiden können, erklären Ihnen unsere Autoren \\ in diesem Tipp.
}

Ein Problem bei der ultraschallgeführten Prostatabiopsie ist die hygienische Verwendung der Punktionshilfe bzw. des Adapters für den Ultraschallkopf. Es handelt sich bei allen Ultraschallgeräten um ein mit Klemmverschlüssen an den Schallkopf angebrachtes halbrundes Kunststoffteil, durch dessen Hohlraum die eigentliche, die Biopsienadel aufnehmende Metallführung läuft. Wird - wie üblich - nur ein einziges Schutzkondom außen angebracht, kommt es häufig zu innenliegenden, schwer zu erkennenden und zu beseitigenden Verschmutzungen mit Blut, Stuhl oder dem Gemisch von beidem mit Ultraschall- oder Anästhesie-Gel.

Hier hat sich unser „Doppelkondom“ bewährt: Eines wird auf den nackten Schallkopf vor Ankopplung der Punktionshilfe aufgebracht, ein zweites darüber. Ohne, dass die Ultraschallsicht sich dadurch verschlechtert, werden Verschmutzungen besser aufgefangen und die hygienische Aufbereitung bzw. Handhabung erleichtert.

\section{Karsten Eisenblätter, PD Dr. Andreas Wiedemann, Witten}
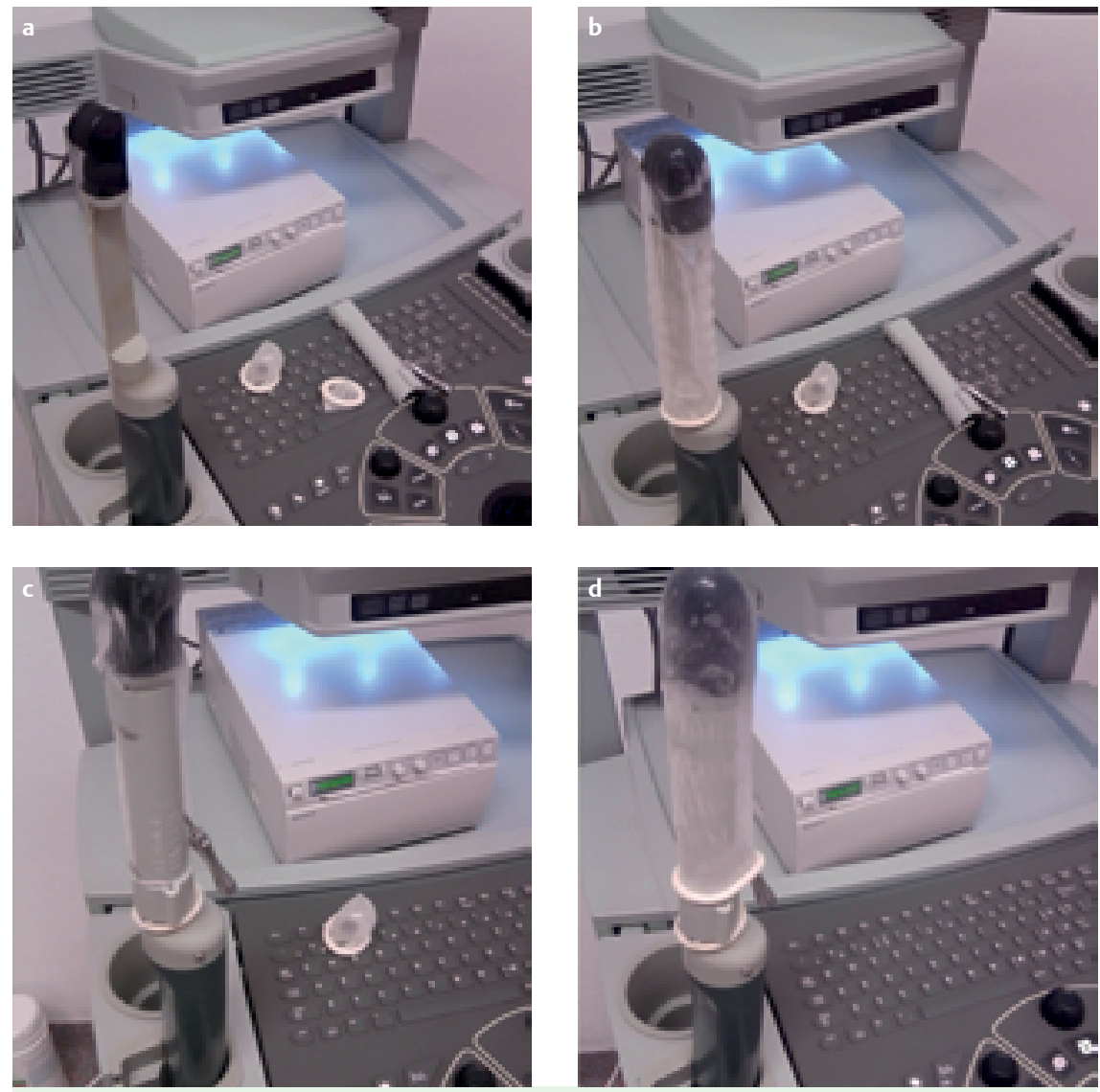

Zusammenbau des rektalen Ultraschallkopfes, der Punktionshilfe und des „Doppelkondoms“.

Korrespondenz:

PD Dr. Andreas Wiedemann

Urologische Klinik

Evangelisches Krankenhaus

im Diakoniewerk Ruhr gGmbH

Lehrstuhl für Geriatrie

der Universität Witten/Herdecke

Pferdebachstr. 27

58455 Witten

Tel.: +49/2302/175-2521

awiedemann@diakonie-ruhr.de

Interessenkonflikte: PD Dr. Wiedemann: Beratungstätigkeit: Dr. Pfleger, Pfizer; Vortragstätigkeit: Allergan, AMS Deutschland, Astellas, Berlin-Chemie, Jansen, Lilly Deutschland, Dr. Pfleger, Pfizer, PohlBoskamp; Studienfinanzierung: AMS Deutschland 